\title{
Air Compressor Control System for Energy Saving in Locomotive Service Plant
}

\section{Wenyu Mo}

Department of Control Science of Engineering, Huazhong University of Science and Technology, Wuhan, China. Email: Mowenyu@gmail.com

Received January $2^{\text {nd }}, 2009$; revised March $12^{\text {th }}$, 2009; accepted March 20 2009.

\begin{abstract}
The actuality and disadvantages of traditional high power asynchronism motor drive air compressor in locomotive service plant are discussed. In order to reduce the energy consumption and obtain safe running, a variable frequency control method to the motor is supplied. A PLC with touch screen is used for monitoring the status of the compressor and its control system. It also presents energy consumption analysis caused by the variable frequency control method in a locomotive service plant.
\end{abstract}

Keywords: Variable Frequency, Air Compressor, Locomotive Service Plant

\section{Introduction}

Air compressor is a key equipment to provide air power, which is driven by asynchronism motor. Air compressor is operated by adjusting rotation speed of the motor. In general, the output air pressure in pipeline of the air tank is acted as controlling object in the system.

The air pressure in the pipeline is controlled to be fluctuate in a certain range. Its upper limit $(0.7 \mathrm{MPa})$ is under the rating pressure of the pipeline, and its lower limit $(0.4 \mathrm{MPa})$ is above the rating pressure of the equipment using the compressive air. Usually, there are two ways to control the air pressure in the pipeline to content this demand.

The first method is starting up and stopping the motor continually for adjusting air pressure in pipeline. When the air pressure is under the upper limit, the air compressor operates until the air pressure goes up to the upper limit, then the motor stops running. But the air pressure will be lowered with air leak or air consuming equipment operating. When the air pressure goes down to the lower limit, the motor begins to work and air compressor operates again. The variable air pressure in the pipeline is shown in Figure 1. This method is simple and low cost, but it is suitable for small power motor because the motor will be started up continually.

The second method is using pressure valve to limit air pressure in the pipeline. When the pressure goes up to the upper limit pressure, the valve will close entrance of the air compressor, then the compressor is in idle state. In this case, the compressor is still driven in operation by the motor, but it does not export compressive air, so the air pressure will not go up further. When the pressure goes down to the lower limit, the valve will be open again, and then the compressor exports compressive air and the air pressure will be up again. The variable air pressure is same as that of the first method. In this case, motor is running continuously, which can be used for high power motor.

In locomotive serve plant, the second method is widely used for control the air pressure from air compressor because of high power motor being used, which rating power is about $100 \mathrm{KW}$. Although the motor is in running operation, its starting up should be controlled. Traditionally, there are two ways to fulfill the starting up, which are linking series resistor in the rotor loop and converting Y- $\triangle$ connection of the starter loop [1]. However, there are still some disadvantages in these two ways as follows.

1) The air pressure in pipeline fluctuates greatly between the upper and lower limits.

2) The continual upload and download of air compressor causes voltage fluctuation in electrical power supply.

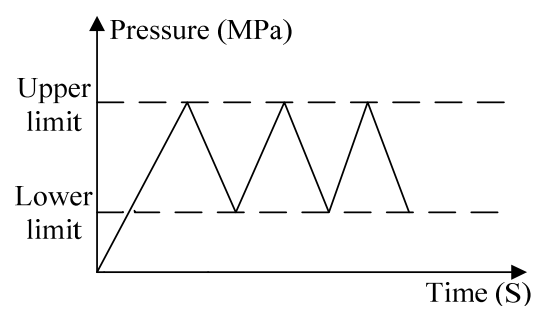

Figure 1. Variable air pressure in pipeline 
3) The air compressor is in full speed rotation all the time, which may lead to mechanical failure and temperature rise.

4) The air compressor and the air pressure valve in their operations cause a great noise pollution.

5) The driving motor of air compressor is inefficient and energy consumptive and cause low power factor.

So, it is necessary to change the traditional control method of the air compressor operation for energy saving, less pollution and low failure possibility.

\section{Variable Frequency Control of Air Compressor Motor}

\subsection{System Principle}

With the rapid development of power electronics technology, transducer is widely used in adjusting speed of AC asynchrony motor [2]. So, a transducer is designed as an executor in the air compressor control system to adjust output air pressure.

In order to control the air pressure in the pipeline, the motor's rotation speed should be in control. However, the motor disables to change its rotation speed itself, the only method is to adjust its frequency to change the rotation speed. So, a transducer used to control the motor's rotation speed, then, the flux from air compressor can be adjusted. The system schematic diagram is shown in Figure 2.

After comparing enactment pressure signal with feedback pressure signal, a pressure signal error is obtained, which is used for calculation of PID arithmetic and then converted the error signal to a control value to adjust frequency of AC power supply. Then the asynchronies motor will drive air compressor to an appropriate rotation speed with variable frequency power supply to eliminate the pressure error and ensure a constant air pressure.

The air pressure adjusted by PID arithmetic in the pipeline is shown in Figure 3. In general, a transducer has an inner PID control unit.

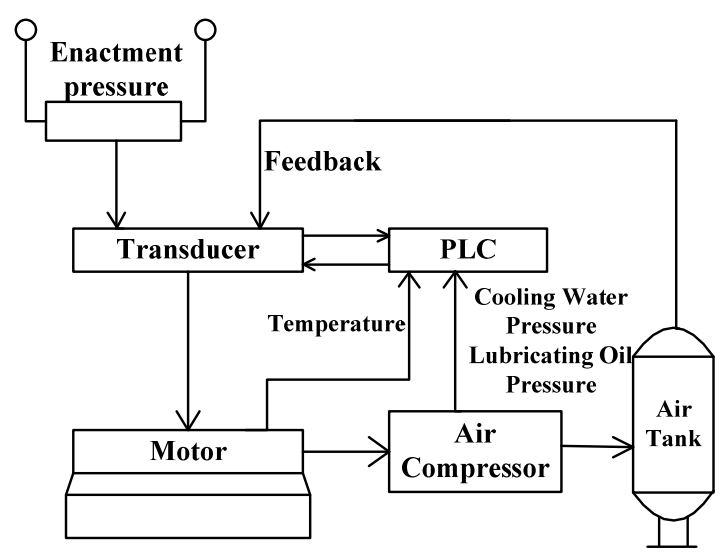

Figure 2. System schematic diagram

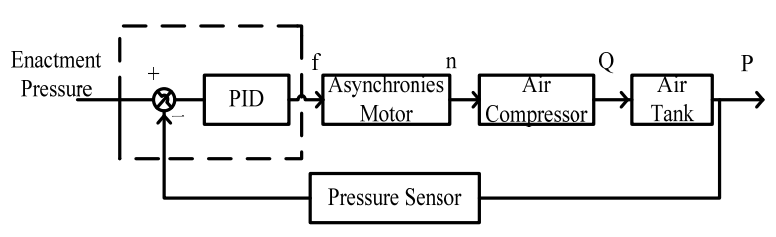

( $\triangle$ =Enactment pressure - Feedback pressure)

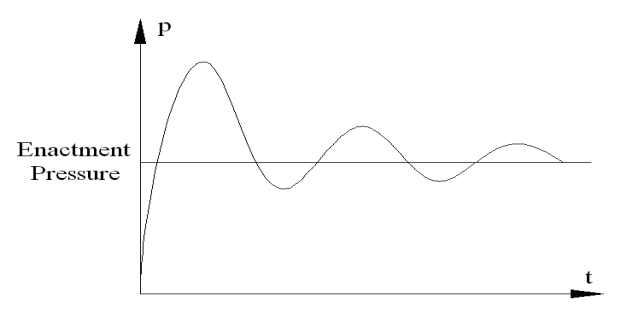

Figure 3. Air Pressure adjusted by PID arithmetic

0 : negative effects, when $\triangle>0$, transducer output frequency raises; $\triangle<0$, frequency declines.

1: positive effects, when $\triangle>0$, transducer output frequency declines; $\triangle$, frequency raises.

When the pressure detected by pressure sensor is higher than the enactment pressure, PID regulator output signal declines and the transducer output frequency falls down, then the air compressor rotation speed reduces and the output air pressure declines; when the detected pressure is lower than the enactment pressure, PID regulator output signal raises and the transducer output frequency increases, then the air compressor rotation speed increases and the output air pressure increases. The system controls the air pressure automatically through the above method.

In Figure 4, a transducer of YASKAMA 616PC5 forms the air pressure feedback control system. On the transducer, FS, FV, FI and FC are ports of pressure enactment and feedback input signal. The FS provides power supply $(+15 \mathrm{~V})$. An input voltage, which determines frequency of AC power supply from the transducer, is linked to the FV port from a resistor $(4.7 \mathrm{~K})$. A feedback voltage of air pressure in the air tank detected by a remote pressure gauge is linked to FI port. These two signals are compared in the transducer and an error can be calculated, by which PID arithmetic is used for calculating control variable. The transducer has self-educated ability, i.e. PID parameters can be adjusted automatically in terms of actual pressure change characteristic in the transducer.

S1, S3, S4 and SC are ports for several control functions. When $\mathrm{K} 1$ is closed, the transducer operates normally. If there is a failure outside the transducer, $\mathrm{K} 2$ will be closed, and the transducer will stop operation. In this 


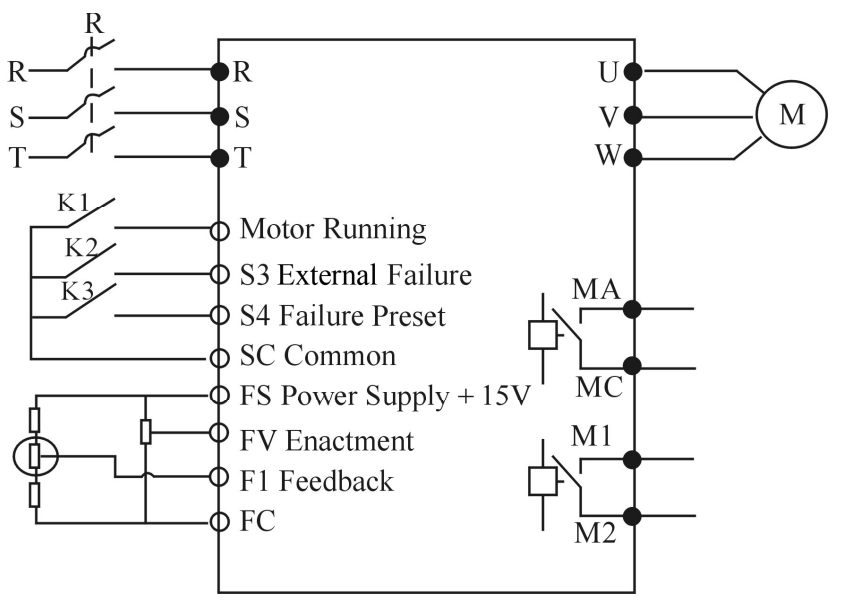

Figure 4. Connection circuit of the transducer

case, a signal can be detected in S3 port to protect the whole system. However, if there is a failure in the transducer, MA and MC ports will be connected in it, by which control system (PLC) can stop the whole system operation. When the failure is removed, control system makes K3 close, a signal inputs to the S4 port, which can reset the transducer. M1 and M2 ports output running state signal. Three-phrase AC power supply are linked to $\mathrm{R}, \mathrm{S}$, and $\mathrm{T}$ ports on the transducer. Then, the variable frequency AC power supply can be exported from $\mathrm{U}, \mathrm{V}$, and $\mathrm{W}$ ports.

A PLC acts as a control unit in the system, from which switches K1, K2 and K3 can output relative signals. Signals from ports M1, M2, MA and MC on the transducer can also be input to the PLC.

\subsection{Existing Problems and Solutions}

Using the transducer would generate harmonic wave. The external input industrial frequency power supply AC $(380 \mathrm{~V} / 50 \mathrm{~Hz})$ is rectified into DC by three-phrase bridge. Finally, it is inverted into any frequency AC power supply by high power transistors after capacitor filtering. In the rectifier circuit, the input current waveform is irregular rectangular wave. The wave is classified into basic wave and harmonic wave based on the Fourier series. The high-order harmonic would interfere with the power supply system, and damages transforms, motors, capacitors, switches and so on.

Solutions for the input side of transducer: 1) setting reactance to increase rectifier impedance for improving the rectifier overlap angle; 2) parallel using AC filter in the power circuit to separate high-order harmonic at all levels respectively from the power supply system.

Solutions for the output side of transducer: using high frequency switch components, adding filter equipments and adopting closed-loop control, using isolation, shielding, grounding and reasonable routing to improve the high-order harmonic interference.
Besides, the starting torque required when the air compressor starts up is large. However, using the conventional method to control will bring damage to other relevant equipments. This system adopts vector control technical to raise the starting torque of motor. Besides, more accurate rotation speed can be gained to control the air compressor. So, almost constant pressure of air can be acquired from this system.

\section{PLC Monitor and Control}

\subsection{Status Parameters Monitored}

Cooling water and lubricating oil are the necessary substances for air compressor running normally. When the air compressor operates, temperature rise of the compressor body can be used to monitor if the compressor runs normally, or not. So, there are three parameters to be monitored in the system, which are pressure of cooling water, pressure of lubricating oil and temperature of the compressor body.

The pressure of cooling water can be used to show cooling system normal operation easily, which includes pump, pipeline and valves. Any problem can cause the pressure abnormal. So, a pressure sensor is mounted at output of cooling water pump for monitoring the whole cooling water system. In the same way, another pressure sensor is used for the lubricating oil monitoring.

As the temperature of compressor body is one of synthetic images to show all malfunctions. In order to measure temperature of the compressor body, a temperature sensor is mounted at the output pipeline of cooling water from the compressor. The temperature of cooling water from the output pipeline is almost equal to the compressor body temperature.

All these sensors are mounted on pipeline outside the compressor, so it is convenient for maintenance and repaired.

\subsection{Design of PLC Monitor and Control}

In order to monitor and control the whole air compressor system, a PLC with touch screen is used [3]. The PLC is composed of power module, CPU module, analog input module, digital input module and digital output module. The configuration of PLC system is shown in Figure 5.

A touch screen is connected to the CPU module, which can display status of the transducer, pressure in the air tank, pressures of cooling water and lubricating oil, and so on. It also can accept many touch instructions instead of mechanical buttons. The CPU module can receive all kinds of data from analog and digital module by interior bus. It also has memory for program and data, and a serial bus RS232C for connecting with a computer.

The power module provides power supplies for every module, which includes $+5 \mathrm{~V}$ and $+12 \mathrm{~V}$ voltages. 


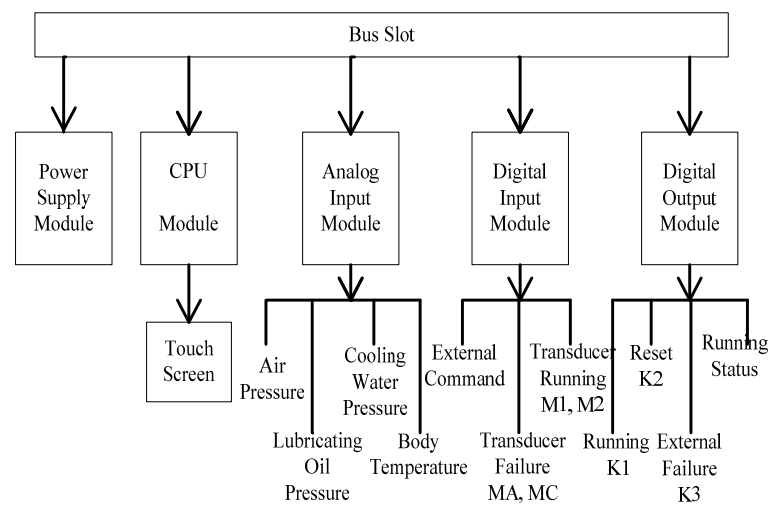

Figure 5. Configuration of the PLC

The analog input module ( $0 \sim+5 \mathrm{~V}$ input) accepts voltage signals from the sensors to measure the compressed air pressure, cooling water pressure, lubricating oil pressure and temperature of the cooling water.

The digital input module (12V input) accepts status signal of the transducer from M1 and M2, failure signal of the transducer from MA and MC, and some operation signals from outside buttons.

The digital output module (relay output) sends out several control signals, which are K1, K2 and K3, operation status signal, and failure signal.

\section{Experimental Results}

We use a PLC and a transducer to rebuild one air compressor control system in a locomotive service plant, which use a high power motor of $75 \mathrm{KW}$ rating power. Its other rating parameters are frequency of $50 \mathrm{~Hz}$, voltage of 380 VAC and current of 150A. We have measured a set of actual parameters of the motor and its power supply at the same regular load condition before and after the rebuilding, which are listed in Table 1 . On the majority of time, the motor can run normally at $42 \mathrm{~Hz}$ frequency of power supply to content air supply requirement of the whole plant.

From the Table 1, it can be shown that current decrease rate is

$$
\begin{aligned}
\delta & =\left(I_{1}-I_{2}\right) / I_{1} \\
& =(117-80) / 117 \\
& =31.6 \%
\end{aligned}
$$

Electricity energy saving rate is

$$
\begin{aligned}
\eta & =\left(P_{1}-P_{2}\right) / P_{1} \\
& =(69.5-39.8) / 69.5 \\
& =42.7 \%
\end{aligned}
$$

\begin{tabular}{|c|c|c|c|c|c|}
\hline Items & $\begin{array}{c}\text { Voltage } \\
\text { (V) }\end{array}$ & $\begin{array}{c}\text { Current } \\
\text { (A) }\end{array}$ & $\begin{array}{c}\text { Fre- } \\
\text { quency } \\
\left(\mathbf{H}_{\mathrm{z}}\right)\end{array}$ & $\begin{array}{l}\text { Rotate } \\
\text { Speed } \\
(\mathbf{r} / \mathbf{m})\end{array}$ & $\begin{array}{l}\text { Input } \\
\text { Power } \\
\text { (KW) }\end{array}$ \\
\hline $\begin{array}{c}\text { AC } \\
\text { Power } \\
\text { Supply }\end{array}$ & 380 & 117 & 50 & 1450 & 69.5 \\
\hline $\begin{array}{l}\text { Trans- } \\
\text { ducer } \\
\text { Power } \\
\text { Supply }\end{array}$ & 320 & 80 & 42 & 1210 & 39.8 \\
\hline
\end{tabular}

As everyday has three shift working time and one year has

$$
\begin{aligned}
\mathrm{W} & =\left(\mathrm{P}_{1}-\mathrm{P}_{2}\right) \times 24 \times 300 \\
& =(69.5-39.8) \times 24 \times 300 \\
& =2.14 \times 10^{5}(\mathrm{KWh})
\end{aligned}
$$

Table 1. Testing parameters $75 \mathrm{KW}$ motor

300 working days, the air compressor control system will save energy in one year as follows.

Obviously, the new system can save lots of energy. Besides, it has other advantages:

1) It reduces greatly noise, realizes soft start and soft stop of the equipment and avoids the shock current of power grid when the air compressor starts up.

2) It has high degree of automation and overcomes the disadvantages of manual adjustment.

\section{Conclusions}

High power air compressor is a kind of equipment widely used in locomotive service plant. In order to save electrical energy and improve operation condition, it is necessary to rebuild traditional control system of high power motor with the transducer and PLC system. In fact the system also has low cost, high reliability and efficiency. It also reduces greatly noise of air compressor operation and possibility of failure. Finally, this system has solved the interference by the high-order harmonic and adopted vector control technique to acquire high starting torque and stabilize motor rotation speed. As the effect of this system is obviously in energy saving, it should be widely used in such a place as locomotive service plant.

\section{REFERENCES}

[1] X. Z. Deng, "Control of electrical and mechanical driving,” Wuhan: Publishing Company of Huazhong University of Science and Technology, pp. 153-178, 2002.

[2] O. Ojo, Z. Q. Wu, G. Dong, and S. Asuri, "Variable frequency control of an induction motor drive with reduced switching devices,” IEEE International Conference on Electric Machines and Drives, San Antonio, TX, United States, pp. 1385-1391, May 2005.

[3] B. Georges and J. Aubin, "Application of PLC for on-line monitoring of power transformers," IEEE Power Engineering Society Winter Meeting, Columbus, $\mathrm{OH}$, United States, Vol. 2, pp. 483-486, February 2001.

[4] A. D Kurtz, et al., "High accuracy miniature pressure transducer," International Instrumentation Symposium, Vol. 470, pp. 303-318, 2007. 